\title{
Criminologie
}

\section{Document : La loi sur les jeunes délinquants et les sénateurs du début du siècle}

Volume 18, numéro 1, 1985

L'histoire du contrôle social

URI : https://id.erudit.org/iderudit/017210ar

DOI : https://doi.org/10.7202/017210ar

Aller au sommaire du numéro

Éditeur(s)

Les Presses de l'Université de Montréal

ISSN

0316-0041 (imprimé)

1492-1367 (numérique)

Découvrir la revue

Citer ce document

(1985). Document : La loi sur les jeunes délinquants et les sénateurs du début du siècle. Criminologie, 18(1), 98-101. https://doi.org/10.7202/017210ar d'utilisation que vous pouvez consulter en ligne.

https://apropos.erudit.org/fr/usagers/politique-dutilisation/ 
DOCUMENT

(Textes choisis et arrangés par Jean Trépanier)

\section{LA LOI SUR LES JEUNES DÉLINQUANTS ET LES SÉNATEURS DU DÉBUT DU SIĖCLE}

L'entrée en vigueur de la Loi sur les jeunes contrevenants il y a moins d'un an, a mis un terme à une loi qui avait présidé pendant trois quarts de siècle à la mise sur pied et au développement des tribunaux pour mineurs au Canadda: la Loi sur les jeunes délinquants.

Adoptée en 1908, par le Parlement canadien, cette loi originait du Sénat, où elle avait fait l'objet de débats en 1907 et 1908 avant d'être rapidement entérinée par la Chambre des communes. Offrons-nous une brève incursion dans l'univers des sénateurs de l'époque.

Tout d'abord, dans quel esprit tentaient-ils de faire adopter le projet de loi? Le parrain de la mesure, le sénateur Scott exprime ainsi ses vues:

Le présent bill a pour objet l'amélioration d'une grande partie de la société, l'amélioration de la morale des enfants qui sont entourés de choses qui conduisent au mal, et il a aussi pour objet de faire adopter des méthodes de procédure qui puissent diminuer chez les enfants la tendance qu'ils ont pour le crime, chez les enfants qui malheureusement vivent dans des logis où ils ont sous les yeux de mauvais exemples ou d'autres choses qui les poussent au vice. (...) Assurément toute réforme qui tend à diminuer le nombre de criminels dans un pays doit intéresser la société et doit faire économiser beaucoup d'argent. Il coûte moins cher de réformer un enfant que de le tenir dans une prison comme criminel. C'est là le principe fondamental du bill. (Débats du Sénat, 1906-1907, p. 880.)

Le sénateur Sullivan abonde dans le même sens :

Il s'agit ici d'éducation. Il s'agit d'empêcher le crime. Le bill se rapporte à l'éducation et il relève naturellement de la législature provinciale. Je ne dis pas cela pour mettre en péril le bill, parce qu'il ne peut y avoir plus noble idée que celle d'aider à l'humanité. Un grand philanthrope a inventé un mot : l'altruisme, L'honorable sénateur qui a conçu ce bill a fait preuve d'altruisme. (Débats du Sénat, 1906-1907, p. 963.)

Le sénateur Béique enchaîne :

Comme l'a si bien dit l'honorable préopinant, la mesure a pour objet d'encourager la philanthropie, de faire porter de l'intérêt aux enfants, de les empêcher de devenir des criminels, de les sauver et de les 
réhabiliter dans leur bas âge et d'en faire de bons citoyens. (Débats du Sénat, 1906-1907, p. 976.)

Et le sénateur Cloran de joindre sa voix au chour unanime :

On a dit que le présent bill était un bill de bienveillance. Il est plus que cela. C'est un bill paternel, et dans chacune de ses lignes circule la bonté du père au lieu de la sévérité du maître qui veut punir l'enfant qui a démérité. (Débats du Sénat, 1906-1907, p. 276.)

L'unanimité n'est cependant pas la même à l'extérieur de la Chambre, ainsi qu'en témoigne le sénateur Coffey:

Au Canada, où nous nous préparons à tenter l'expérience un de nos officiers de police, le sous-chef Archibald de la police de Toronto nous conseille comme suit :

Gardons-nous soigneusement de ces gens à marotte, superficiels et sentimentaux qui cherchent à profiter de la popularité de cette propagande en faveur de l'enfant pour surprendre les sympathies et la bonne foi des philanthropes des deux sexes dans le but d'introduire dans notre législation un système abortif et sans consistance qui ferait descendre le juge au niveau de l'incorrigible gamin de la rue et l'obligerait à prendre une attitude répulsive aux sujets britanniques. Ils semblent croire que, par l'emploi copieux de l'argot, le juge doit se mettre en état d'amadouer et de dorloter une classe de jeunes délinquants pervertis dont on ne saurait réformer le caractère qu'à l'aide d'une discipline inflexible et par une méthode de correction rationnelle. Je vais plus loin et me basant sur une longue expérience, $j$ 'affirme que cette flatterie, ces caresses, prodiguées sans discernement, même aux enfants de la meilleure classe, auraient des effets désastreux, tout à la fois sur leur physique, leur mentalité, leur moralité et leur spiritualité. (Débats du Sénat, 1907-1908, p. 1057.)

Qu'à cela ne tienne, poursuit le sénateur Coffey :

Les gens qui partagent l'opinion du sous-chef Archilbald se basent, cependant, je pense, sur le système d'administrer la justice qui prévalait autrefois en Angleterre. Il y eut un temps où les jeunes délinquants comparaissaient devant quelques juges anglais du genre de "Old Bailey", à la physionomie morose, encadrée d'une perruque, au regard pénétrant comme les rayons $X$, qui semblait traverser jusqu'à l'âme la tremblante épave du pavé aux yeux de laquelle s'éveillaient de formidables visions de Newgate. Mais c'est de l'histoire ancienne, et l'on ne trouve plus nulle part cette crainte de se montrer clément qui caractérisait autrefois les cours de justice, et qui a contribué à nous donner un Dickens. L'esprit d'inflexibilité et de sévérité qui semble se dégager de l'opinion de M. Archibald ne s'implantera point, je l'espère, au Canada. Il est bien vrai qu'il y a lieu, à certaines heures, d'appliquer la loi avec sévérité, mais il n'en est pas moins vrai qu'il convient toujours de prêter l'oreille 
à la voix de la clémence qui s'élève en faveur de la pauvre humanité déchue. (Débats du Sénat, 1907-1908, p. 1057.)

Les sénateurs peuvent-ils s'appuyer sur l'autorité de la criminologie pour trancher le débat? Le sénateur Lougheed décrit les ressources dont le gouvernement dispose :

Dans presque tous les départements il y a des éndits et des experts qui s'occupent de méthodes scientifiques qui peuvent s'appliquer aux choses animées et inanimées, et cependant dans le département de la justice, le département qui est spécialement chargé de s'occuper de la loi criminelle, il n'y a pas, à ma connaissance, un seul officier revêtu du pouvoir d'étudier les grands questions sociales et économiques qui concernent les classes criminelles de la société. J'ai cherché dans le rapport du département de la Justice pour voir si l'on s'y occupe de pareilles questions; mais je n'ai pu constater que l'on s'adonnait à la science de la criminologie. (Débats du Sénat, 1906-1907, p. 897.)

S'il faut donc aller chercher ailleurs, où puiser les connaissances relatives à la délinquance juvénile? Le sénateur Lougheed répond :

... dans un livre qui a été écrit sur les jeunes délinquants par M. Douglas Morrison, qui est considéré en Angleterre comme la meilleure autorité en criminologie. (Débats du Sénat, 1906-1907, p. 897.)

Morrisson a largement été oubliê depuis lors, malgré une réimpression récente de son Juvenile Offenders (Patterson-Smith, 1975). On doit en dire autant de ces sénateurs que Platt aurait compté parmi ses child savers eût-il étudié la situation canadienne. Même le sénateur Scott, l'initiateur du projet de loi, alors secrétaire d'État dans le gouvernement de Laurier, qui en dépit de ses 82 ans domina une partie des débats, est aujourd'hui relativement peu connu. Pourtant, le sénateur Cloran n'avaitil pas dit de lui qu'avec l'adoption d'une telle loi :

... son nom passera à la postérité comme celui d'un législateur qui a voulu faire un acte utile à son pays. Ce n'est pas la première fois que son nom se trouve identifié avec des lois qui ont contribué beaucoup à améliorer la vie sociale au Canada et à rendre les conditions de la vie sociale meilleure qu'elles l'aurait été sans ses efforts. Son nom est identifié avec l'acte Scott*, qui, bien qu'il n'ait pas eu de succès partout, a rendu, durant les trente dernières années, de grands services à la société. Son nom se trouvera attaché à cette législation-

\footnotetext{
* Législation sur la tempérance, adoptée en 1878, qui permettait à certaines conditjons de prohiber la vente d'alcool dans une ville ou un comté.
} 
ci. Il a essayé de sauver les vieux quand il était jeune, et maintenant qu'il est vieux il veut sauver les jeunes. (Débat du Sénat, 1906-1907, p. 976.)

Se trouvera-t-il un jour quelqu'un pour faire un tel panégyrique des parlementaires qui, soixante-quinze ans plus tard, auront fait adopter la Loi sur les jeunes contrevenants? Les générations à venir devraient bien, elles aussi, pouvoir regarder leurs prédécesseurs avec un certain sourire. 